\title{
Large Stone "Hoes"
}

by G. Watson, Pense

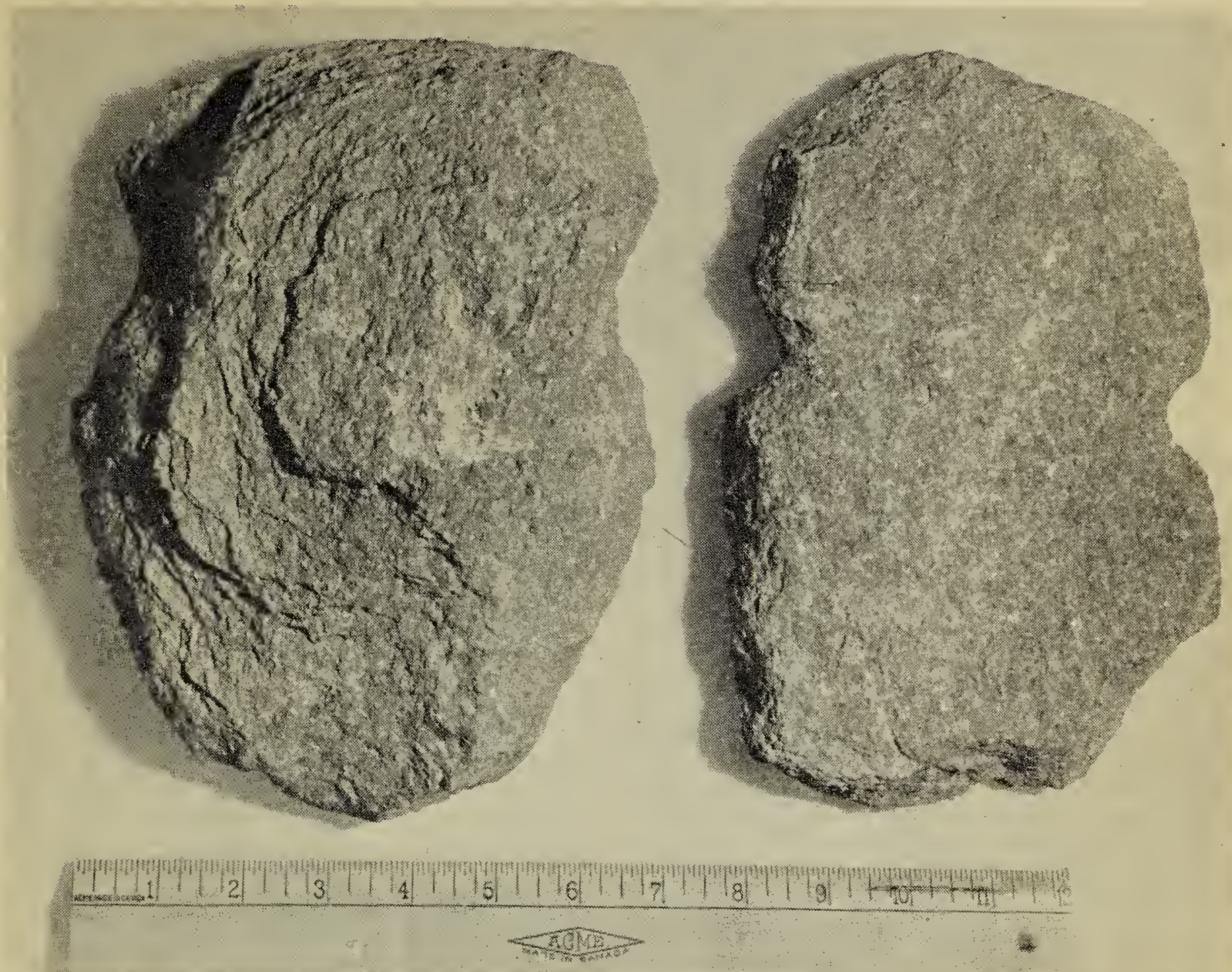

Saskatchewan Museum of Natural History Photo

Large stone "hoes" from Squaw Rapids (left) and Grand Coulee (right).

I recently had the pleasant surprise of being presented with the above pictured artifact for addition to my archaeological collection. Herein is my thanks to the donors. Mr. Frank Vancise, whose farm is located southwest of Grand Coulee, found it while working a field on the $\mathrm{NE}^{1 / 2}$ of Sec. 20, T16, R21, W2 during the spring of 1960. Vancise presented it to Mrs. J. Smith of the Regina Rock and Gem Society. Mrs. Smith was kind enough to permit the author to place the artifact in his collection of Saskatchewan pre-historic material.

The artifact is a rather crude stone "hoe" made by placing rounded triangular notches on icppositie sides of a leaf of foliated coarse-grained meitamorphosed sandstone, which is peppered grey and white in colour. No lateral groove connecting the notches, which occurs on most "hoes," is discernible. The outer edge of the stone has been trimmed to shape by pressure-flaking. The flakes were removed on alternate faces and the whole abraded to a rough working edge. The lower right hand corner of the specimen has been broken laterally to the cleavage plane, suggesting a sharp glancing blow either in use or as a result of modern cultivation of its original resting place. As far as is known at this time, this artifact represents the only material from this locality; for purposes of cataloguing it has been given the Borden system \#EcNf-1 and catalogued as \#1 (EcNf-l/1).

A very similar artifact was discovered by Wally Mollberg of Nipawin, when accompanying Thomas $\mathbf{F}$. Kehoe, Provincial Archaeologist, on a survey of the Squaw Rapids reservoir area in late May, 1960. Through the kindness of Kehoe, its description is included in this article. 
This specimen is also a large pebble of foliated, coarse-grained, pink and black metamorphosed granite, with intrusive veins of quartz crystals throughout. The outer edge again has been roughly flaked to shape. The grooves and the somewhat pointed tip are the only areas showing rubbing action. The tip has had extensive use as there is a great deal of polishing in this area.

It will be noted that the term "hoes" has been used in the descriptions of these artifacts, until this type of tool has been more thoroughly studied in this area the term is arbitrarily applied. It is known that similar implements were used in agricultural pursuits in other areas of the world, but as yeit insufficient numbers have been studied to prove or disprove their supposed use as hoes here.

\section{DIMENSIONS IN MILLIMETERS}

\begin{tabular}{|c|c|c|}
\hline & $\begin{array}{l}\text { Grand } \\
\text { Coulee } \\
\text { "Hoe" " }\end{array}$ & $\begin{array}{l}\text { Squaw } \\
\text { Rapids } \\
\text { "Hoe"" }\end{array}$ \\
\hline & $\mathrm{mm}$ & $\mathrm{mm}$ \\
\hline 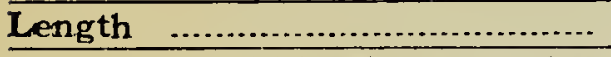 & 280.0 & 230.0 \\
\hline Maximum width above notches & 145.0 & 164.0 \\
\hline Maximum width at notches .... & 120.0 & 142.0 \\
\hline Maximum width below notches & $\begin{array}{r}155.5 \\
\text { tape } \\
\end{array}$ & $\begin{array}{r}173.0 \\
\text { ering to } \\
108.5 \\
\end{array}$ \\
\hline 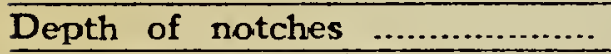 & 13.5 & 11.5 \\
\hline Width of notches ...................... & 32.0 & 41.0 \\
\hline Maximum thickness ................... & 19.5 & 54.0 \\
\hline Minimum thickness ................ & 18.0 & 29.0 \\
\hline Weight & $\begin{array}{l}\text { grams } \\
1,231\end{array}$ & $\begin{array}{l}\text { grams } \\
2,813 .\end{array}$ \\
\hline
\end{tabular}

It is hoped this small article will point out again the importance and value of amateur collections as an aid to the professional archaeologist studying an area. Our duty as amateurs is to make sure he sees a neatly labeled, catalogued and stored collection, rather than an accumulation of "curios" and "Indian Relics." In this way we can contribute a small part to the story of Saskatchewan prehistory, now being written.

\section{HUGE SPEAR BLADE FOUND}

\section{by A. J. Hruska, Gerald}

A distal end of a spear blade of remarkably large proportions has been found in this district. It was found by Orton Buckberger on NW 9-20-32 W1 in the spring of 1960 . It was found under a large boulder when stones were being removed from a cultivated field prior to seeding operations.

This specimen, of which only about three-quarters was found, is $12.8 \mathrm{~cm}$ long, $8.0 \mathrm{~cm}$ wide, $1.2 \mathrm{~cm}$ thick at the broken edge, and slightly thicker towards the point. It has a twist. The flaked edges are quite sharp. It is made of brown chalcedony (flint). It is our opinion that it was hafted and not used as a hand tool.

The land on which this antifact was found is classified geologically as moraine deposit, quite likely deposited by the last continental ice-sheet. The fact that this artifact was found under a large rock leaves us with the impression that it is of great age. Is it possible that the last ice-age covered this spear point indicating an aboriginal culiture five times as old as either the Mortlach or Long Creek cultures?
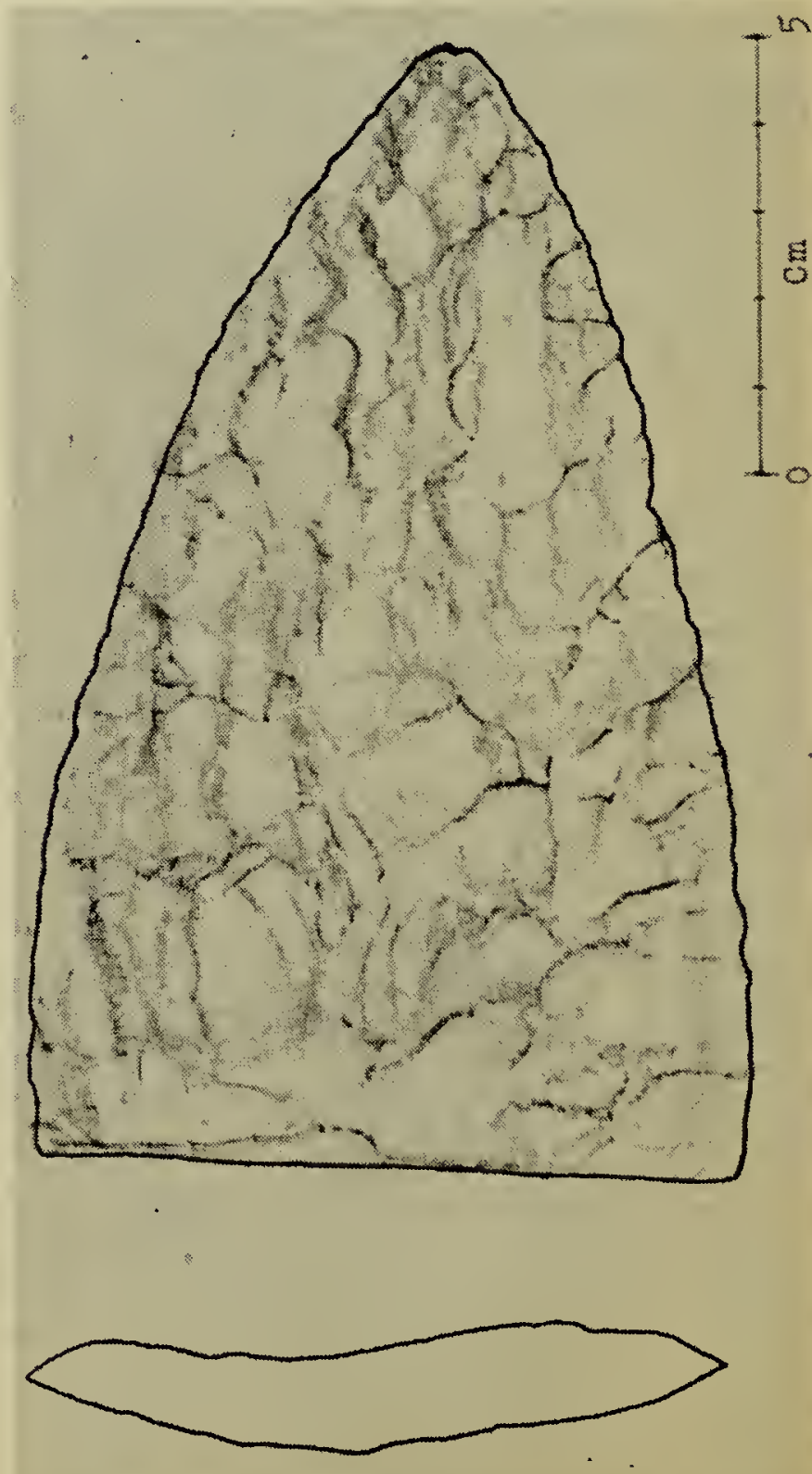